\title{
Pancreatic hypoplasia-diabetes-congenital heart disease syndrome
}

INSERM

\section{Source}

INSERM. (1999). Orphanet: an online rare disease and orphan drug data base. Pancreatic hypoplasia-diabetes-congenital heart disease syndrome. ORPHA:2255

Pancreatic hypoplasia-diabetes-congenital heart disease syndrome is characterized by partial pancreatic agenesis, diabetes mellitus, and heart anomalies (including transposition of the great vessels, ventricular or atrial septal defects, pulmonary stenosis, or patent ductus arteriosis). 